\title{
Huge Dentigerous Cyst in the Maxillary Sinus: A Rare Case in Childhood
}

\author{
Case Report $>\begin{aligned} & \text { Övsen Önay (D), Ahmet Emre Süslü (D), Taner Y1lmaz (D) } \\ & \text { Department of Otorhinolarynogology, Hacettepe University School of Medicine, Ankara, Turkey }\end{aligned}$
}

Abstract

ORCID IDs of the authors: 0.0. 0000-0002-8009-0311; A.E.S. 0000-0002-3345-5066; T.Y. 0000-0001-8999-3237.

Cite this article as: Önay Ö, Süslü AE, YıImaz T. Huge Dentigerous Cysts in the Maxillary Sinus: A Rare Case in Childhood. Turk Arch Otorhinolaryngol 2019; 57(1): 54-6.

This study was presented at the $13^{\text {th }}$ International Otorhinolaryngology - Head and Neck Surgery, April 5-7, 2018, Ankara, Turkey.

\section{Corresponding Author:}

Övsen Önay; ovsenonay@yahoo.com

Received Date: 03.08 .2018 Accepted Date: 17.11.2018

๑) Copyright 2019 by Official Journal of the Turkish Society of Otorhinolaryngology and Head and Neck Surgery Available online at www.turkarchotolaryngol.net DOI: 10.5152/ta0.2019.1920
Dentigerous cyst (DC) is the second most common type of odontogenic cyst. It is thought to have a developmental origin, arising from an anomaly in the reduced dental epithelium. Rarely seen in early childhood, DC is mostly prevalent among people aged between 20 and 40. The most common location of DC is the mandibular third molar, more rarely occurring in the maxillary sinus. Enucleation is the standard treatment. Herein, we report an 11-year-old boy with DC that developed into the maxillary sinus, measuring $5 \times 2.5 \times 1.7 \mathrm{~cm}$. We also present an evaluation of the diagnosis and treatment of this type of DC.

Keywords: Odontogenic cyst, maxillary sinus, computed tomography, pediatric dentistry

\section{Introduction}

Dentigerous cyst (DC), also known as follicular cyst, is the second most common form of odontogenic cysts after radicular cyst (1). Thought to be developmental in origin, DC is caused by an anomaly in the reduced dental epithelium (2). DC is formed by the force exerted by the exudate that accumulates between the reduced dental epithelium and the tooth crown. It is related to a partially erupted or impacted tooth, and it is most commonly seen in the third molars of the mandible (70\%). Other common locations of DC are the third molar teeth of the maxilla, the maxillary canines, and the premolars of both jawbones (3). Though more rarely, DCs are also associated with the supernumerary tooth. DCs caused by an impacted supernumerary tooth localized in the anterior maxilla account for only $5.5 \%$ of all the DC cases, and those that spread into the maxillary sinus are even more infrequent $(2$, 4). DC is commonly seen in the 20 to 40 age group. It rarely affects children (4). DCs are usually asymptomatic except for the cases where there is infection or expansion. In the event of infection, it can cause a painful swelling. In the case of an expansion into cortical plates, DC can cause facial asymmetry, and precipitate a destruction of the adjacent tissues.

\section{Case Presentation}

An 11-year-old boy was referred to our department with a painless swelling on his face that grew gradually in the past two months. The patient was followed-up for ataxia telangiectasia, a recessively inherited rare systemic disorder that results in a progressive neurological decline. There was no history of allergic symptoms. In the physical examination, a non-tender, rigid swelling localized on the right maxillary sinus was identified. A slight facial asymmetry was also obvious. There was a mediolateral expansion from the lateral wall of the nasal cavity to the arch of the zygomatic bone, and a superoinferior expansion from the infraorbital rim to the upper lip. Intraorally, the swelling presented an expansion from maxillary right central incisor to the premolar teeth. The mucosa covering the swelling seemed intact. Maxillary anteriors appeared to be viable and responsive to percussion. No signs of trauma or dental procedure were visible around the lesion. All facial and cranial nerves of the patient were undamaged, and no neck lymph nodes were detected during palpation. Computerized tomography (CT) examination revealed a large rounded lesion with well-defined borders, measuring $5 \times 2.5 \times 1.7 \mathrm{~cm}$ in the right maxillary 


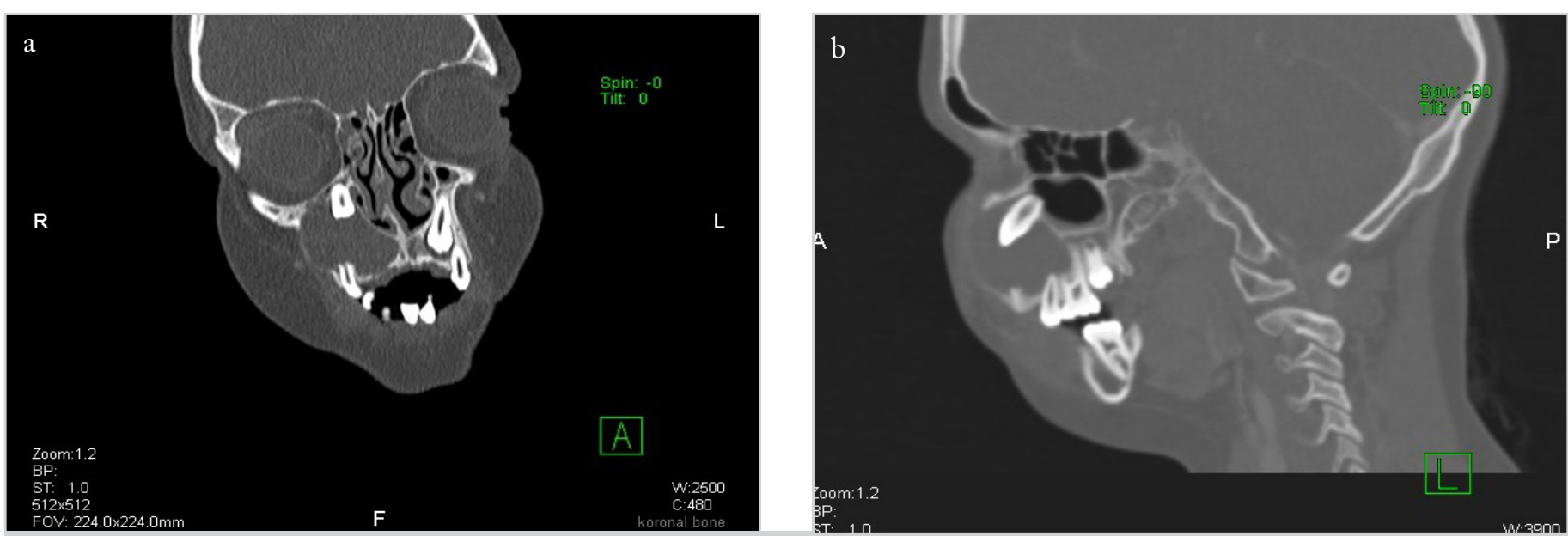

Figure 1. a, b. Computed tomography (CT) coronal section demonstrating a soft-tissue mass occupying and spanning the entire right maxillary sinus and involving a supernumerary tooth (a). CT scan, sagittal section demonstrating a soft-tissue mass occupying and spanning the entire right maxillary sinus and involving a supernumerary tooth $(\mathrm{b})$

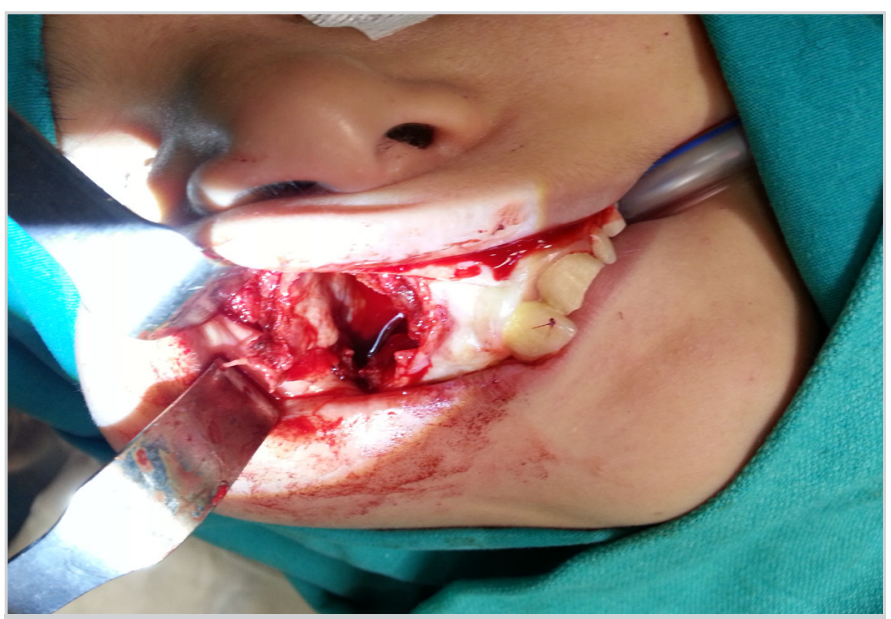

Figure 2. Defective anterior maxillary wall, destroyed by cyst expansion

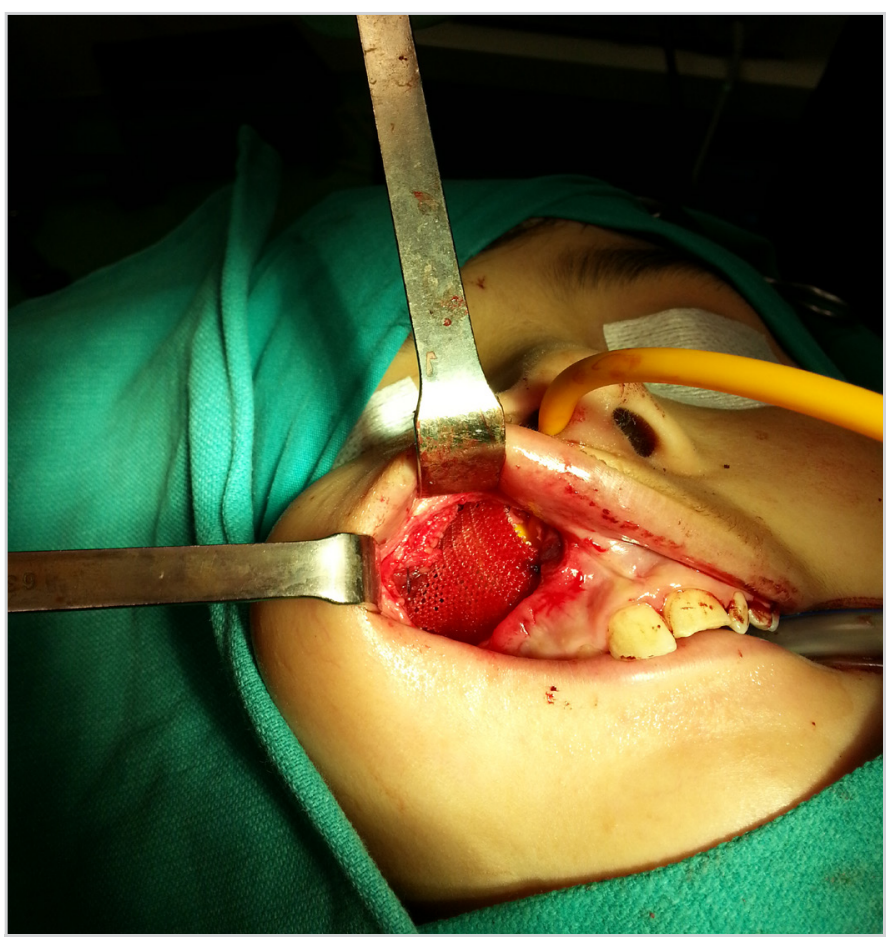

Figure 3. Anterior maxillary wall defect repair with an absorbable mesh

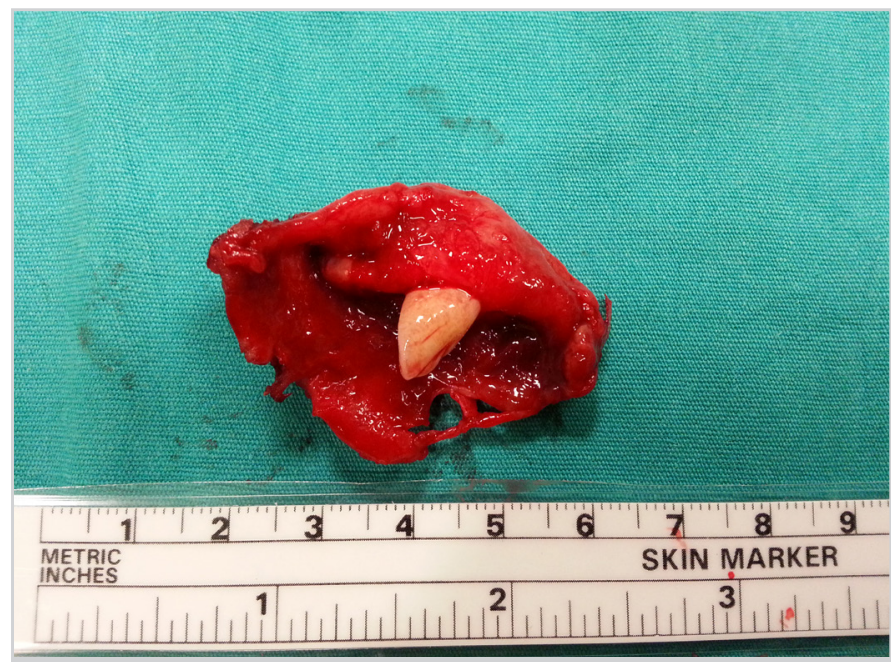

Figure 4. Post-operative view of the specimen consisting of a cyst with a small monoradicular supernumerary tooth

sinus. The lesion was surrounded by soft tissue and contained a supernumerary tooth (Figure 1). The patient was diagnosed with an infected DC associated with a supernumerary tooth in the maxillary sinus. No abnormalities were seen in the results of the routine blood tests. The patient was then operated under general anesthesia. Caldwell-Luc antrostomy was performed during the enucleation procedure. An incision was made from the right lateral incisor to the right second premolar tooth, and a full thickness mucoperiosteal flap was elevated at the right mucobuccal fold. Under the flap, we observed that the anterior maxillary wall, adjacent to the frontal process of the maxillary bone, was destroyed by cyst expansion (Figure 2,3). The frontal process of the maxilla and the zygomatic bone was healthy. We elevated the cysts surrounding the epithelium from the internal wall of the maxillary sinus. Histopathological examination of the specimen revealed the existence of a cyst with a small single-rooted misshapen supernumerary tooth, confirming the initial diagnosis (Figure 4). The patient was discharged from the hospital after one day of close follow-up. Post-operative clinical follow-up that was conducted after one month of the surgery was uneventful. 


\section{Discussion}

Dentigerous cysts affect the roots of the teeth (radicular cysts). The incidence of DCs is $14 \%-20 \%$. They are slightly more prevalent among males (1.6:1) (5). DCs are most frequently seen in the mandible (70\%) and the maxilla (30\%) (5). DC's peak incidence is seen among people who are in their 20s and 30s (23\% and $20 \%$, respectively). As was the case in our patient, only a small percentage of DCs occur in the first decade of life $(5,6)$.

The exact histogenesis of DC is unclear, but some histopathological pathways have been described. DC attaches itself to the neck of the tooth (cementoenamel junction) and encloses the impacted tooth. The pressure applied by the emerging tooth on the dental sac blocks the venous outflow, causing the serum to rapidly pass through capillary walls. This accumulated fluid exerts an increasing hydrostatic pressure and detaches the dental arc from the crown of the tooth (6). The enlargement of the DC is associated with the proliferation of the epithelial cells, release of bone-resorbing factors, and the osmolality of the fluid within the cyst (7). Therefore, although being asymptomatic, DC can manifest itself with swelling on the face, inflammatory rhinorrhea, nasal malformation, and excessive tearing in the eyes when localized to the maxillary region (7). All of these symptoms were present in our patient.

Dentigerous cysts in the maxillary sinus are easy to detect radiographically due to their opacity. In these cases, panoramic radiography is a suitable method to be used in daily practice because of its low cost and simplicity. Panoramic radiographs are very effective in distinguishing the existence of a tooth, if any, in DC. CT scan can also help to detect bony structures and understand the definite size or content of the lesions in the maxillary sinus (7). A differential diagnosis is also possible where DCs can be distinguished from odontogenic keratocyst, ameloblastic fibroodontoma, ameloblastic fibroma, calcifying epithelial odontogenic tumor, adenomatoid odontogenic tumor, and unicystic ameloblastoma (7).

The standard treatment for a DC in the maxillary region is enucleation and tooth extraction by using Caldwell-Luc antrostomy. However, in cases where the cyst is larger, marsupialization technique can be adopted after routine enucleation procedure to prevent further damage on osseous structures. A major drawback of using this technique is that the lesion can recur or persist around the cystic borders. Endoscopy, which decreases the rate of morbidity during and after such operations, can also be used for the treatment of the DCs in the maxilla (7). Due to the size of our patient's cyst, we did not prefer an endoscopic approach. When there is chronic infection, DC can develop into ameloblastoma or squamous cell carcinoma and mucoepidermoid carcinoma (8). Therefore, initial clinical and radiographical ex- amination is of paramount importance to make an early and accurate diagnosis, as well as to follow the appropriate treatment procedure.

\section{Conclusion}

During differential diagnostic processes, odontogenic cysts including DCs must be taken into account, particularly in cases of rapidly growing cysts with expansion and erosion of bony walls in the maxillary sinus.

Informed Consent: Written informed consent was obtained from the parents of the patient.

Peer-review: Externally peer-reviewed.

Author Contributions: Concept - A.E.S., Ö.Ö.; Design - Ö.Ö., A.E.S.; Supervision - T.Y., A.E.S.; Resource - A.E.S., Ö.Ö., T.Y.; Data Collection and/or Processing - A.E.S., Ö.Ö.; Analysis and/or Interpretation - A.E.S., Ö.Ö.; Literature Search - Ö.Ö., A.E.S.; Writing - Ö.Ö., A.E.S.; Critical Reviews - A.E.S., T.Y.

Conflict of Interest: The authors have no conflicts of interest to declare.

Financial Disclosure: The authors declared that this study has received no financial support.

\section{References}

1. Guruprasad Y, Chauhan DS, Kura U. Infected dentigerous cyst of maxillary sinus arising from an ectopic third molar. J Clin Imaging Sci 2013; 3: 7. [CrossRef]

2. Jiang $\mathrm{Q}, \mathrm{Xu}$ GZ, Yang C, Yu CQ, He DM, Zhang ZY. Dentigerous cysts associated with impacted supernumerary teeth in the anterior maxilla. Exp Ther Med 2011; 2: 805-9. [CrossRef]

3. Bonardi JP, Gomes-Ferreira PH, de Freitas Silva L, Momesso GA, de Oliveira D, Ferreira S, et al. Large dentigerous cyst associated to maxillary canine.J Craniofac Surg 2017; 28: e96-e97. [CrossRef]

4. Xu GZ, Jiang Q, Yang C, Yu CQ, Zhang ZY. Clinicopathologic features of dentigerous cysts in the maxillary sinus. J Craniofac Surg 2012; 23: e226-e231. [CrossRef]

5. Zhang LL, Yang R, Zhang L, Li W, MacDonald-Jankowski D, Poh CF. Dentigerous cyst: a retrospective clinicopathological analysis of 2082 dentigerous cysts in British Columbia, Canada. Int J Oral Maxillofac Surg 2010; 39: 878-82 [CrossRef]

6. Khandeparker RV, Khandeparker PV, Virginkar A, Savant K. Bilateral maxillary dentigerous cysts in a nonsyndromic child: A rare presentation and review of the literature. Case Rep Dent 2018; 15: 7583082-88. [CrossRef]

7. Taysi M, Ozden C, Cankaya AB, Yildirim S, Bilgic L. Conservative approach to a large dentigerous cyst in an 11-year-old patient. J Istanb Univ Fac Dent 2016; 50: 51-6. [CrossRef]

8. Kilinc A, Gundogdu B, Saruhan N, Yalcin E, Ertas U, Urvasizoglu G. Odontogenic and nonodontogenic cysts: an analysis of 526 cases in Turkey. Niger J Clin Pract 2017; 20: 879-83. 